\title{
Teaching Partners:
} Improving Teaching and Learning by Cultivating a Community of Practice

\author{
Richard A. Holmgren \\ Allegheny College
}

The Teaching Partners Program and its follow-up activities demonstrate that a carefully designed faculty development program can shift a campus culture to derive significant, measurable benefits for faculty and students. The program seeks to transform the institutional culture from one in which teaching is sequestered behind closed doors to one that supports substantive conversations about both the learning-teaching process and the methods by which that process might best be facilitated. Following Shulman's (1993) lead, the program opens the doors of the classroom, reenvisions teaching as community property, and nurtures informed and sustaining discussion of teaching.

\section{INTRODUCTION}

7 he Teaching Partners Program responds to a faculty needs assessment with 1 an integrated program that meets both faculty needs and enhances the learning experiences of students. Program components-an intensive workshop, class visits, and ocher events-are designed to reinforce one another and to provide faculty with the rewards necessary to sustain their participation. Our assessment of the program considers the impacts on the participants, their students, and the institution, and it demonstrates that the Teaching Partners Program has positive outcomes for the reaching experience of participants, the learning experiences of their students, and the larger college community. 


\section{Defining the Campus Culture: A Needs Assessment}

In the spring of 1999, Professor of English Lloyd Michaels and Associate Professor of Mathematics Richard Holmgren were appointed as dean and associate dean of the college, respectively, at Allegheny College, a residential liberal arts college in northwestern Pennsylvania with approximately 130 faculty and 1,850 students. To prepare for their new administrative roles and to assess the needs of the faculty, Michaels and Holmgren interviewed individually over $90 \%$ of the full-time tenured or tenure-track faculty. Eighteen of the 24 tenure-track but not yet tenured faculty that we interviewed expressed a desire for more support for teaching, including workshops focused on teaching, formative observation and discussion of their teaching with colleagues, and structured opportunities to visit the classrooms of colleagues. Untenured faculty also indicated that in all but one department, informal discussion of issues and successes encountered in teaching was largely absent. These findings are consistent with views expressed by many tenured faculty who suggested that teaching is something that is done behind closed doors. One senior faculty member reported that he saw no need to assist new hires with developing their teaching, claiming that "we hired them because they are already good teachers and scholars." Like many faculty at institutions involved in the American Association for Higher Education Peer Review of Teaching Project, faculty at Allegheny readily sought and were offered assistance for their research, but many viewed teaching as a personal enterprise that does not benefit from being shared (Hutchings, 1996).

Teaching Partners was created to change this perception of teaching, and it draws on another need identified in faculty interviews-a need for community that values all facets of our work, including teaching. Faculty frequently reported a sense of isolation and a concomitant desire for connecting to a community of colleagues. A senior Teaching Partners participant illustrated this sense of isolation in an interview with an external consultant by describing a time when he would go to the dining hall and converse over lunch with colleagues; today he eats a yogurt at his desk because there is no time for a more leisurely break (Foster, 2000). On another occasion, a faculty member who has been a teaching innovator on campus was asked to consider preparing his work for publication or presentation at a conference on teaching and technology. He acknowledged that his findings were worth disseminating, but demurred, stating, "I don't want this kind of work to be what l'm known for on campus." Our needs assessment demonstrated that faculty desired but were not finding a community that supported their teaching. In fact, at least some faculty feared that they might lose the respect of their peers if they publicly joined such a community. 


\section{Responding to the Challenge: Creating a Program to Meet the Needs}

Teaching Partners seeks to change the campus culture with respect to learning and teaching by providing faculty opportunities to learn about current research on learning and how it applies to their work, opportunities to share their teaching practice and explore new strategies in the company of colleagues, and opportunities to enhance their skills as supporters of one another's teaching. Faculty apply to the program, and 12 program participants are selected for the program each year. A representarive cohort of the broader faculty is created in each program year by selecting from a range of disciplines and ranks. To facilitate institutional transformation and build credibility, faculty leaders, who Middendorf (2000) would call opinion leaders, are encouraged to participate each year. To date, 45 faculty have participated in the program, 22 of whom are women, 14 were tenured at the time they enrolled, and 22 were in their first three years of service when they enrolled in the program. Five faculty have left the college since participating in the program. Even so, nearly one-third of Allegheny's continuing full-time faculty are program participants.

In each program year, the 12 program participants engage in three activities: a weeklong summer workshop, exchanges of class visits during the academic year, and regular events for program participants to exchange ideas and build community. In the workshop, faculty refine their understanding of their students and human learning, learn and practice new teaching and course design strategies, and learn and practice techniques for providing hclpful feedback about teaching to colleagues. Microteaching, in which participants present short teaching segments to one another and then receive feedback, is a primary component of the workshop and provides a laboratory in which faculty can test new teaching strategies, receive feedback on their teaching, and practice providing feedback about teaching to colleagues. During the academic year following the summer workshop, program participants exchange class visits and feedback with other members of the Teaching Partners Program. In these exchanges, participants further refine their teaching strategies and their ability to provide helpful feedback to colleagues. A serics of discussions, lunches, and social events that are scheduled throughout the year and open to all program alumni provide participants venues to explore teaching related matters, to create the community infrastructure necessary to sustain a shift in the institutional culture.

The program design also recognizes that change in a campus culture cannot be mandated; it grows out of activities in which faculty willingly engage and which provide the intrinsic rewards necessary to sustain interest and 
commitment (Erickson \& Erickson, 1979; Golin, 1990; Tiberius, Sacklin, Janzen, \& Preece, 1993). Wergin (2003) asserts that faculty are motivated by four underlying desires: autonomy, community, efficacy, and recognition. Teaching Partners honors faculty autonomy: All participants are volunteers, and faculty have wide latitude in deciding how they fulfill the program requirements. The program builds community by incorporating common attendance at a workshop and shared classroom observations into the program structure and by regularly providing opportunities for substantive conversation about teaching. The increased teaching skill and confidence fostered by the program enhances participants' sense of efficacy. And regular positive references to the program and its success by the dean of the college and the college president recognizes the contributions of its participants.

\section{Documenting Change: Assessing Program Impact}

Our assessment is intended to document the impact of the program on the teaching experiences of the participants, on the learning environment of their students, and on the culture of the institution. Before participating in the program, participants are interviewed individually by external evaluators with extensive experience in qualitative educational research. After participation, program faculty are interviewed annually in focus groups by the same evaluators. Interviews and focus groups are taped, transcribed, and coded by the evaluators and a report highlighting themes is sent to the director of the Teaching Partners Program.

Student experience is assessed by comparing the responses of students who have taken three or more courses from Teaching Partners participants on the National Survey of Student Engagement (NSSE) to the responses of students who have not taken courses from Teaching Partners participants. Since we do not have sufficient baseline data, we are unable to compare the response of students to participants' courses before they participated to the response of students to participants' courses after they participated, which is unfortunate. However, we have compared the response of students to participants' courses on a locally developed teaching evaluation form before participation in the program to the response of students to participants' courses after participation. Finally, we have compared the retention rates of first-year students who took courses from Teaching Partners participants in the fall semester of their first year to the retention rates of first-year students who did not take courses from program participants. The comparison of retention rates was done both before and after participation. To assess the impact on the campus culture, we 
have collected information through surveys, focus groups, interviews, and close observation of faculty behavior.

\section{IMPACt ON FaCULTY: Improving aNd RENEWING Teaching}

Now in its fourth year, the comments of participants in focus groups and meetings indicate that the Teaching Partners Program has fostered positive changes in participants' teaching and on-campus experiences. When asked about the program in focus groups with external evaluators, participants describe specific improvements in their teaching that are direct outgrowths of participating in Teaching Partners. For example, participants indicate that they are more aware of the different learning styles of students and as a result more likely to incorporate a mix of active learning strategies into their courses. They report increased use of collaborative learning strategies, class discussion, student designed projects and assignments, exams that are reflective or require higher order thinking skills, and classroom assessment tools such as minute papers. They also report that they are more likely to ask students to reflect on and search for improvements in their learning strategies.

Participants indicate that the workshop is particularly helpful, and that the follow-up activities sustain the momentum they gain at the workshop. Many untenured participants comment that involving faculty of all academic ranks and from many different divisions affirms for them that teaching is important to the institution and central to what we do. However, although the program has been helpful for untenured faculty and was designed with them in mind, its impact on faculty has been most dramatic for faculty with 10 or more years of teaching experience.

One faculty member who had been teaching at Allegheny for 12 years at the time she applied to the program indicated

I like what I am doing more. I look forward to going to my classes and teaching in a way that I haven' for quite some time.... I think getting positive feedback with reassurance, both during the summer course and since, has made me feel like, yeah, I can do this and I can do this well. Thinking about my course more in advance and what I want to accomplish and how the pieces come together has made me more excited about going and putting it into practice. (Teaching Partners, 2000)

Another experienced colleague regularly goes out of his way to thank the program director for encouraging him to atrend the summer course and to tell the director what new teaching strategies he is employing and how much more 
he is enjoying his teaching. Such renewed enthusiasm for teaching and learning is typical of the response of tenured participants, and participants from all years continue to be active in campus discourse about teaching, at faculty meetings, in workshops for the general education faculty, and in committees focusing on curricular development and assessment.

\section{IMPACT ON STUDENTS: \\ IMProving LearNing EXPERIENCES AND SATISFACTION}

Preliminary data on student response to the courses of Teaching Partners participants indicate that these changes are leading to improvements in students' experiences and the learning environment. An analysis of student responses on the 2001 NSSE indicates that students of Teaching Partners participants are engaging in more practices that correlate with increased student learning than are other students at Allegheny. For example, students who took three or more courses from a Teaching Partners participant are more likely to report that their courses emphasize applying theories and concepts, and less likely to emphasize facts, ideas, or methods. Although the data set is small and not every observed shift is statistically significant, nearly all of the observed shifts are in the desired direction and in every case where the observed difference is statistically significant, it is in the desired direction. In particular on the 2001 NSSE, students who had taken three or more courses from a Teaching Partners participant in the past year were significantly more positive about the statement that that they would choose to attend Allegheny were they given the choice over again $(\mathrm{p}=.03)$.

The students' enthusiasm for attending Allegheny correlates with our finding that the retention rate of the 178 first-year students who took a course in the first semester of their first year from a faculty member who had participated in Teaching Partners was better than the retention rate of the 383 firstyear students who took no courses from Teaching Partners that semester, with rates of $90.0 \%$ and $87.0 \%$, respectively. By contrast, the retention rate of the 187 first-year students who took a course in the first semester of their first year from a faculty member who would later participate in Teaching Partners was only slightly better than the retention rate of the 346 first-year students who took no courses from faculty who would be Teaching Partners that semester, with rates of $85.8 \%$ and $85.0 \%$, respectively.

A comparison of student responses on Allegheny's locally developed course evaluations revealed that students in participants' courses after participation in the program responded more favorably than students in participants' courses before participation. In particular, students in the courses of 
Teaching Partners after they had completed the workshop were significantly more likely to report that the instructor challenged them to actively engage the material than students in the courses of Teaching Partners before they participated in the program $(p=.01)$. Students' overall rating of instructors also improved, although the improvement was not statistically significant in one of the two cohorts of Teaching Partners participants for which we have completed data analysis ( $p=.02$ for the 2001 cohort). Students also reported that they learned more, the instructor was more available, assignments were more helpful, and the instructor's comments were more helpful in the courses of Teaching Partners participants after they participated in the program; but again, in most cases, these differences were not significant. Interestingly, the time and effort that students report applying to the courses of Teaching Partners participants remained essentially unchanged after program participation.

We continue to collect data on student experiences with Teaching Partners participants, and given current trends in the data, we expect to find more statistically significant positive shifts when data collection and analysis is completed.

\section{Impact on the College Culture: Expanding a Community of Practice}

The experiences of participants and their students indicate that Teaching Partners is meeting its goal of improving teaching and learning at Allegheny College. However, the larger challenge is to parlay the faculty enthusiasm generated among program participants into a more sustaining and sustainable institutional culcure that supports teaching and learning. As the proportion of Allegheny faculty who participate in Teaching Partners grows, efforts to institutionalize the culture being promoted by the program are increasing. In particular, a practice of shared classroom observations based on the Teaching Partners model is being promored through workshops, conversations with department heads, and encouragement from the dean's office and the faculty review committee; a program of weekly lunch meetings focused on teaching has been successfully launched; and the dean and associate dean of the college seek to develop faculty mentoring networks in the coming year. Each of these initiatives involves collaborative work related to teaching and promotes faculty autonomy and community and faculty efficacy by enhancing faculty skills and self-confidence.

Response to the newly developed weekly lunch meetings, which we call Teaching Circles, suggests that faculty continue to seek opportunities to share their experiences in the classroom and to learn from one another. The circles are modeled on groups facilitated by Steve Golin at Bloomfield College (personal 
communication, October 12,2001 ) and differ from more traditional teaching circles or brown-bag lunch discussions in several ways: The circles are agendaless, and participants are asked to talk about whatever joys or challenges they are currently facing in their teaching. Participants commit to attending every week for an entire semester so that over the course of 12 or more meetings they can build the trust necessary to sustain a substantive and challenging dialogue. Participants are asked to focus on what they bring to the classroom as teachers (as opposed to complaining about the students), and they are asked to hold the contributions of other participants in confidence.

The pilot circle was extraordinarily successful. Participant attendance was near perfect, and all 12 of the original participants asked to continue with the group for a second semester. When the formation of a second circle was announced via email, 10 faculty asked to join within 5 hours. Within 4 days, 16 faculty asked for one of the 12 places at the table. As a result, in the second semester of the program, nearly $20 \%$ of Allegheny's tenured and tenure-track faculty were engaged in an ongoing discussion of teaching that was independent of Teaching Partners. The program continues to be fully subscribed with two circles of 12 faculty meeting each week.

The enthusiasm for these lunch meetings suggests that the college is succeeding in creating a culture in which faculty appreciate the value of good talk about teaching. Over half of the college's tenured or tenure-track faculty have participated in either Teaching Partners or Teaching Circles, so we are reaching well beyond the cohort of "early adopters." By sustaining and institutionalizing these efforts and continually searching for new opportunities to provide the supportive community sought by faculty, we are creating a responsive faculty culture that supports faculty, teaching, and student learning.

\section{Conclusions}

Transformational change in the academy requires focus, patience, and time, but Allegheny College's experiment demonstrates that it can be done. Structuring faculty development activities to foster organizational change can yield significant and sustainable benefits to faculty, students, and the institution. There is ample evidence to support our claim that Allegheny College's faculty development programs enhance the teaching experience for individual faculty and foster a sense of community and shared mission among program participants. Analysis of student reports on national and locally developed assessment instruments, as well as retention data for first-year students, indicates that these changes have positive benefits for students. Sustained and widespread faculty involvement in ongoing teaching development programs demonstrates that 
these benefits are being extended to the larger college community. However, cultural change in the academy cannot be mandated. To be welcomed by the faculty, it must respond to their felt needs. To expand beyond a limited circle, it must include a representative cross-section that includes faculty leaders. To be sustainable, it must provide faculty the autonomy, community, efficacy, and recognition they seek.

\section{Note}

This work was supported by grants from the William and Flora Hewlett Foundation and the Andrew W. Mellon Foundation.

\section{ReFERENCES}

Erickson, G. R., \& Erickson, B. L. (1979). Improving college teaching: An evaluation of a teaching consultation procedure. Journal of Higher Education, 50, 670-683.

Foster, S. (2000). Teaching partners program: Analysis of first interviews. Unpublished report.

Golin, S. (1990). Peer collaboration and student interviewing: The master faculty program. AAHE Bulletin, 43(4), 9-10.

Hurchings, P. (1996). The peer review of teaching: Progress, issues, and prospects. Innovative Higher Education, 204), 221-234.

Middendorf, J. K. (2000). Finding key faculty to influence change. In M. Kaplan \& D. Lieberman (Eds.), To improve the academy: Vol. 18. Resources for faculty, instructionah and organizational development (pp. 83-93). Bolton, MA: Anker.

Shulman, L. S. (1993. November/December). Teaching as community property: Purting an end to pedagogical solitude. Change, 25(6), 6-7.

Teaching Partners Lunch Discussion. (2000, October 13). Unpublished tape transcript.

Tiberius, R. G., Sacklin, H. D., Janzen, K. R., \& Preece, M. (1993). Alliances for change: $A$ procedure for improving teaching through conversations with learners and partnerships with colleagues. Journal of Staff. Program, and Organizational Development, 11(1), 11-22.

Wergin, J. F. (2003). Departments that work: Building and sustaining cultures of excellence in academic programs. Bolton, MA: Anker. 